\title{
Pulsating patches: a model for the spatial and temporal dynamics of the threatened seagrass Halophila johnsonii
}

\author{
Robert W. Virnstein ${ }^{1,3, * * *}$, Lee-Ann C. Hayek ${ }^{2, * *}$, Lori J. Morris ${ }^{3}$ \\ ${ }^{1}$ Seagrass Ecosystems Analysts, 142 Elgin Road, East Palatka, Florida 32131, USA \\ ${ }^{2}$ Smithsonian Institution, NHB MRC-121, Washington, DC 20560, USA \\ ${ }^{3}$ St. Johns River Water Management District, Palatka, Florida 32178, USA
}

\begin{abstract}
The Indian River Lagoon (IRL), FL, USA, is arguably the most biologically diverse estuarine system in the continental USA. An important part of any marine ecosystem, seagrass beds provide food, habitat, and nursery for both vertebrate and invertebrate inhabitants. Their high productivity and sensitivity to water quality changes make seagrasses primary indicators of overall coastal ecosystem health. Halophila johnsonii (Johnson's seagrass), currently federally listed as a threatened species, is one of the rarest seagrass species, and is found within the IRL usually only approximately between Sebastian and Jupiter Inlets, continuing south to northern Biscayne Bay. Quantitative data for the present study is a subset of the monitoring of all 7 seagrass species in the IRL starting in 1994 with $1 \mathrm{~m}^{2}$ quadrats placed every $10 \mathrm{~m}$ along each transect from shore to the deep edge of the seagrass bed. The present study reports long-term data for $H$. johnsonii from the 35 transects within its range in the IRL sampled continuously (summer and winter) from 1994 through 2007. Our objective was to provide insight and to test hypotheses about the dynamic nature of $H$. johnsonii. In addition, we developed an index of retrospective effect size to assess the importance of ecological factors and their interactions as well as to develop a comparative basis for future seagrass studies. This erratic, sparse, but persistent species increased slightly in coverage over time but with accompanying high variability so that regional stability over time is maintained by local unpredictability. Summer abundance on average appears to follow a 2 to $3 \mathrm{yr}$ increase, then a single year's precipitous decrease over the $14 \mathrm{yr}$ of our summer observations. Based upon the results from this long-term and thorough data set, we propose a new model of asynchronous, 'pulsating patches' in both space and time for describing the long-term survival strategy of $H$. johnsonii.
\end{abstract}

KEY WORDS: Halophila johnsonii - Seagrass - Indian River Lagoon - Seagrass transects Spatial dynamics - Temporal dynamics · Pulsating patches · Effect size $\cdot$ Long-term monitoring

Resale or republication not permitted without written consent of the publisher

\section{INTRODUCTION}

The Indian River Lagoon, Florida (IRL), which spans over $250 \mathrm{~km}$ and straddles the transition zone between tropical and subtropical, is part of the longest barrier island complex in the USA occupying approximately $30 \%$ of Florida's Atlantic coast. In 1990, the US Environmental Protection Agency designated the IRL as an 'estuary of national significance'. Gilmore (1985) argues that this system is the most biologically diverse estuarine system in the continental USA, and preservation of its biodiversity is of great concern.

Halophila johnsonii (Johnson's seagrass) is one of the smallest of the 7 species of seagrass in the IRL, averaging only $3 \mathrm{~cm}$ in height (Fig. 1, Table 1). It cannot be distinguished by remote sensing. Even in the field, identification of $H$. johnsonii requires close inspection both to detect it and to distinguish it from a similar 


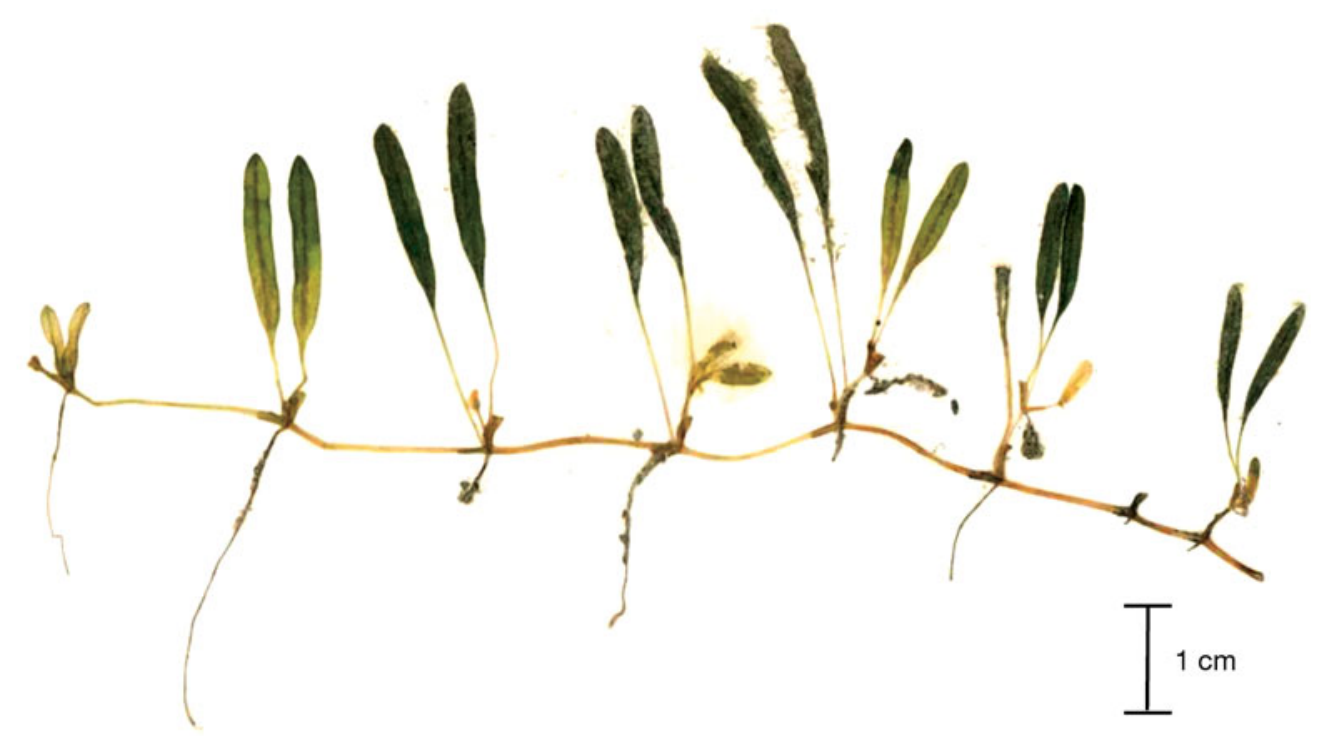

Fig. 1. Halophila johnsonii, illustrating leaf and rhizome size, apical meristem (far left), and rhizome branching. See Table 1 for distinguishing characteristics

species, H. decipiens. It is characterized by pairs of elongate linear leaves with smooth margins and a brown mid-rib (Fig. 1, Table 1). In contrast, H. decipiens, which often co-occurs with $H$. johnsonii, has obovate, bright green leaves and finely serrated margins.

Halophila johnsonii is the rarest seagrass species, with the most limited range of the approximately 60 species of seagrasses in the world. It is found only in southeast Florida, within the IRL region approximately from Sebastian Inlet to Jupiter Inlet, and continuing south to northern Biscayne Bay (Kenworthy 1992). In an intensive search, $H$. johnsonii was recently (August 2007) found $21 \mathrm{~km}$ north of Sebastian Inlet (Virnstein \& Hall 2009). Because it was not found at transect sites, this northern extension of the range was not included in our analyses here. Although first collected prior to 1960 (Phillips 1960), H. johnsonii was not described as a new species until 1980 (Eiseman \& McMillan 1980). Given the apparent lack of sexual reproduction, H. johnsonii probably recruits only by vegetative fragments (Hall et al. 2006). Based on its rarity, limited

Table 1. Halophila johnsonii. Distinguishing blade characteristics (see Fig. 1)

\begin{tabular}{|ll}
\hline Blade characteristic & \multicolumn{1}{c}{ Description } \\
\hline Shape & Linear, length $>5 \times$ width \\
Color & Light green, with brown mid-rib \\
& and veins \\
Margins & Smooth \\
Surface & No hairs \\
\hline
\end{tabular}

distribution, and lack of known male plants or sexual reproduction, $H$. johnsonii is federally listed as a threatened species (Kenworthy 1992, NMFS 2002).

Broad-scale distributions (tens of kilometers or greater) of seagrass species are driven by geographic gradients such as temperature, salinity, depth, substratum, and water currents over differing scales of both space and time. Local species distribution is then modified by local gradients and biological interactions. We examined each of these factors in order to determine the combination of survival strategies utilized by Halophila johnsonii under the highly variable conditions of the lagoonal estuaries of the southeast coast of Florida. Based upon our extensive spatial and temporal observational data, we also present a range of values for expected 'effect size' useful for this and future studies of seagrass dynamics. More importantly, we propose a new model of asynchronous, 'pulsating patches' in space and time to describe best the temporal and spatial dynamics of $H$. johnsonii.

The objective of this study is to test hypotheses concerning the dynamic nature of Halophila johnsonii using our 14 yr summer/winter dataset from 35 fixed transects in the Indian River Lagoon within the range of $H$. johnsonii, from Sebastian Inlet to Jupiter Inlet. These null hypotheses are that there is a lack of pattern in (1) overall long-term increase or decrease in density, (2) seasonal distribution or density, (3) distribution of density versus depth, (4) density in relation to the distribution and density of other seagrass species.

In summary, we examine our ability to predict the occurrence and density of Halophila johnsonii over space and time. 


\section{MATERIALS AND METHODS}

Field methods. The primary technique for monitoring seagrass abundance and species composition in the IRL, including Halophila johnsonii abundance, is the use of $1 \mathrm{~m}^{2}$ quadrats along fixed transects monitored in 2 seasons, summer (June-July) and winter (JanuaryFebruary) (Virnstein \& Morris 1996, Morris et al. 2001). The period of our monitoring study is summer 1994 through summer 2007. Out of a total of 88 transects lagoon-wide, we established 35 fixed transects within the known range of $H$. johnsonii in the Lagoon. Seagrass sites (Fig. 2) were selected from aerial photos and have been continuously monitored, summer and winter, since 1994. All transects extend from shore to the deep edge of the seagrass beds. At $10 \mathrm{~m}$ intervals, (1) water depth, (2) percent cover, and (3) canopy height of each species is measured within a $1 \mathrm{~m}^{2}$ quadrat. Each quadrat is divided by strings into 100 cells, each $10 \times 10 \mathrm{~cm}$

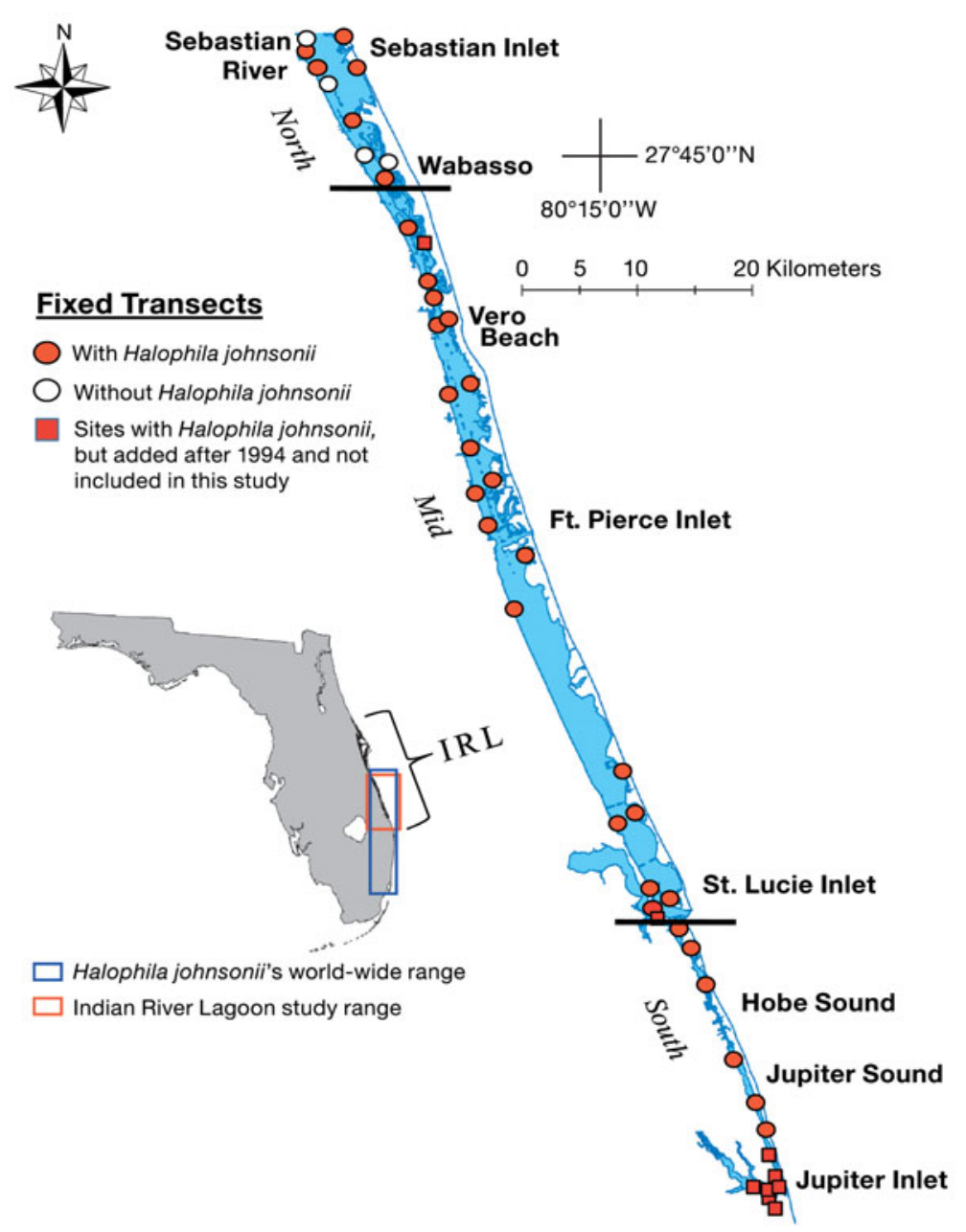

Fig. 2. Halophila johnsonii. Range and distribution along the east coast of Florida. Transect sampling sites in the Indian River Lagoon, with (0) and without (O) H. johnsonii. Sites added since 1994 ( $\square$ ) were not included in analyses. Heavy black lines separate North, Mid, and South regions
(Morris et al. 2001). 'Percent cover' or 'coverage,' as used here, is not conventional canopy cover, but rather is measured as a count of the number of cells in each quadrat that contain each species of seagrass, also referred to as 'local frequency' (Greig-Smith 1983). Additionally, as a rapid and easy measure of density, 'visual estimates' of canopy percent cover are made based on how many cells would be filled if all the seagrass shoots in the quadrat were visually 'pushed' to fill cells with dense coverage. Inter-observer error was minimal for this visual estimate after training was completed.

Replicate observations were obtained within regions under conditions of homogenous or similar environmental conditions along the length of the IRL by segregating the sites into 3 geographic regions: North (Sites 39 to 48), Mid (Sites 49 to 68), and South (Sites 69 to 73) (see Fig. 2). These regional boundaries were based on homogeneity of environmental conditions (seagrass, water quality, and flushing rates) within each region.

Statistical methods. Transect monitoring from 1994 through 2007 represents a continuous, complete seasonal, and yearly sequence. We were therefore able to fit general linear models (GLM) with ANOVA, regression, and covariance models to this data set. The dataset consisted of 9681 quadrat samples from the 35 transects within the known range of Halophila johnsonii. Variance assumptions were first tested with Hartley's F-max test. Missing data were eliminated from analyses. Before analysis, percent cover was transformed to natural $\ln (x+1)$ to stabilize the variance. Computations for both descriptive and inferential statistical analyses were completed with SPSS (SPSS 2007). Null hypotheses for differences over time and space were tested. We modeled the data both with and without zero values. The former dataset provided information on all measured presences and absences of $H$. johnsonii for those hypotheses involving rarity and behavioral patterns, while the latter dataset provided information on characteristics of $H$. johnsonii only where and when it was actually sampled as present.

Measurements of depth were taken at each quadrat site. For purposes of comparative analyses, a new variable of standardized depth was calculated. Standardized depth for each quadrat is the percent of maximal depth, taken at the deep edge of that transect. Therefore, since a relative measure of depth was used, no correction for water level was necessary. We then divided this new standardized depth variable into 10 equal depth categories. 
Power and 'effect size' for ANOVA modeling. It is often advocated that a statistical power analysis be performed on data. However, power is most appropriately used before the field or experimental design, not retrospectively. Retrospective power, calculated for an analysis using the 'effect size' (Cohen 1977, Hayek \& Heyer 2005) of that analysis, gives the same basic information as the $\mathrm{p}$-value. Power can only be successfully used if there is an estimate of the expected effect size for the particular study and set of study organisms or observations. Effect size is a simple standardized way of quantifying the difference between groups. Effect size has many advantages over the use of tests of statistical significance alone. For the present study, the use of effect size emphasizes the actual ecologically meaningful difference rather than confounding this difference with sample size.

Different measures or indices of effect size have been proposed for prospective and retrospective study. For describing how ecologically meaningful a result is in terms of how large the effect is, the most popular measures are based on the degree of association between an effect and the dependent variable, based on regression analysis. Partial eta-squared (PES) is our effect size measure of choice because it is the proportion of the biological effect variance plus error variance that is attributable to the effect we observed, and also describes the amount of variance accounted for in the sample.

Statistical significance ( $p$-value) for a hypothesis indicates whether the results could be due to chance or to sampling variability. Total reliance upon a $\mathrm{p}$-value, without regard to sample size, leads to incorrect conclusions; results are more likely to be significant for large sample sizes. With over 9000 observations in this monitoring study, we would expect there to be significance. A combination of non-significance of the test result based upon small sample size, with large PES would show that sample size was the root of the ambiguous test result and did not indicate ecological truth. Alternatively, a significant test result based upon a large sample but with a PES value near zero says that the result is an ecological anomaly. That is, despite statistical significance, the actual difference between the tested values is too minute to be considered to be ecologically meaningful. Thus, statistical significance is not necessarily substantive significance.

Since effect size measures are dimensionless, our usage of effect size provides a way to evaluate not only the results of this study but future seagrass monitoring efforts. We also used this measure to provide a basis for expected size of effects in future seagrass work, which in turn can become the preliminary basis of sample size determination.
Throughout this paper $\alpha$ indicates the test or probability level of the statistical test and $\mathrm{p}$ denotes the observed probability level obtained after the significance test was performed.

\section{RESULTS}

\section{Total variability}

Throughout most of its range, Halophila johnsonii is discontinuous and rare, relative to other seagrass species. Its occurrence varied both among and within transects. H. johnsonii occurred at 31 of the 35 fixed transects within the range of this study in the IRL, that is, Sebastian Inlet to Jupiter Inlet, but at not more than 23 transects at any one sampling time, and as infrequently as once. At no transect was it present on all sampling dates. Although $H$. johnsonii has recently been reported farther north (Virnstein \& Hall 2009), we consider this a recent expansion. Because $H$. johnsonii was not found along transects in this expanded range we did not include it in this study.

There were 9681 quadrats sampled for Halophila johnsonii in our $14 \mathrm{yr}$ period. Mean \pm SD coverage was $2.9 \pm 13.2 \%$ (Table 2). Of the total 9681 samples, 8853 of these, or $91 \%$, were zero. For those samples in which $H$. johnsonii coverage was greater than zero $(\mathrm{N}=828)$, the mean observed coverage was $33.7 \pm 31.4 \%$ (Table 2). Of this total, $75 \%$ of the quadrats had less than $54 \%$ coverage, $50 \%$ had less than $22 \%$ coverage, and $25 \%$ had less than $7 \%$ coverage. All these data emphasize the rarity of this species.

Modeling of all Halophila johnsonii data $(\mathrm{N}=9681)$ with factors of year, season, and interaction with a linear model approach yielded significant hypothesis test results for each factor and interaction, except season $(p=0.099)$. Although it is commonly accepted that the density of $H$. johnsonii varies seasonally (NMFS 2002), there were no detectable seasonal differences using all 9681 observations. With such a large total sample size, significance invariably was expected and achieved, except for season. Observed power was consistently high, approximately 1.00 in each case.

For the test of overall seasonal differences, PES = 0.000 . Likewise, when factors of depth category or geographic region and interaction were included in the model, each achieved significance because of the large total $\mathrm{N}$, while the PES values were all near zero, including seasonal effects within depth category.

Introducing covariates of depth or distance from shore into the potential models did not alter this picture. Consideration of a statistical covariate in a general linear model is a commonly used statistical adjustment. This approach can examine variability 
over samples under a condition of constant value for the covariate factor, e.g. depth (observed or standardized) or distance from shore.

The hypothesis of equality over sites was not accepted, even though the PES value for site differences was substantial at 0.223 . The PES for the interaction of year and site was 0.153. Individual site differences were not tested because the large number of tests required and small sample sizes precluded testing.

However, an examination of the individual sites appeared to show differences among them within the geographic region of the IRL. That is, the magnitude of the differences among the sites within a region varied among regions. Therefore, instead of examining individual site differences, each with varying but small degrees of freedom, we used North, Mid, and South regions (Fig. 2). Neither Scheffé's one-degree of freedom test nor predictive analyses could tease out the Mid range as significantly different from the other 2 areas. Therefore, when examining questions of regional differences, we used only the significantly distinct North and South regions.

\section{Variation over years}

Between 1994 and 2007, there were 9681 quadrats sampled (= 'samples') for Halophila johnsonii in the IRL along transects within the range of this species (Virnstein \& Morris 1996, 2007). Table 2 presents

Table 2. Total quadrats sampled (N) of Halophila johnsonii in Indian River Lagoon, Florida, 1994-2007, with descriptive statistics by year: $N$, mean percent cover, and coefficient of variation. Average of summer and winter for 2 datasets: with all data, and only non-zero data. NB Only summer data were available for 1994

\begin{tabular}{|ccccccc|}
\hline \multirow{2}{*}{ Year } & \multicolumn{3}{c}{ N } & \multicolumn{2}{c}{ Mean (\%) } & \multicolumn{2}{c|}{ CV (\%) } \\
& All & Non-zero & All & Non-zero & All & Non-zero \\
\hline 1994 & 397 & 31 & 2.02 & 25.81 & 5.03 & 1.05 \\
1995 & 661 & 17 & 0.66 & 25.53 & 10.22 & 1.36 \\
1996 & 751 & 22 & 0.89 & 30.50 & 8.07 & 1.13 \\
1997 & 890 & 85 & 3.36 & 35.15 & 4.18 & 0.88 \\
1998 & 877 & 88 & 4.01 & 39.93 & 4.09 & 0.88 \\
1999 & 907 & 64 & 1.45 & 20.56 & 5.32 & 1.04 \\
2000 & 855 & 61 & 2.03 & 28.49 & 5.33 & 1.05 \\
2001 & 673 & 64 & 2.95 & 30.97 & 4.35 & 0.95 \\
2002 & 689 & 58 & 2.10 & 24.91 & 5.24 & 1.19 \\
2003 & 552 & 62 & 3.84 & 34.19 & 3.85 & 0.89 \\
2004 & 582 & 101 & 5.77 & 33.26 & 3.04 & 0.88 \\
2005 & 522 & 22 & 1.63 & 38.68 & 6.49 & 0.92 \\
2006 & 608 & 52 & 3.72 & 43.44 & 4.03 & 0.70 \\
2007 & 717 & 101 & 6.13 & 43.52 & 3.27 & 0.78 \\
Total & 9681 & 828 & 2.88 & 33.66 & 4.60 & 1.07 \\
\hline
\end{tabular}

descriptive statistics by year both for all data and for those samples in which $H$. johnsonii had non-zero coverage.

Regression of coverage over year on total $\mathrm{N}$ values was non-significant $\left(r=-0.19, R^{2}=0.04\right)$. The mean coverage increased significantly over time $(r=0.62$, $\mathrm{R}^{2}=0.38, \mathrm{p}=0.009$ ), accompanied by highly variable but significant increase in the standard deviations $(\mathrm{r}=$ $\left.0.63, R^{2}=0.40, p=0.008\right)$, but with consequent decreases in coefficients of variation (CVs) $(r=-0.54$, $R^{2}=0.30, p=0.022$ ). The effect of year was highly significant in a modeling of all data $(p=0.000$, PES $=$ $0.121, \mathrm{~N}=9681)$. This model included factors of site $(p=0.000, P E S=0.223)$ and interaction $(p=0.000$, PES $=0.153)$. For each of these factors the PES values were considerable, indicating a substantial effect of year, site, and interaction.

Results for only the non-zero values did not change significantly over time $(r=0.41)$. However, CV significantly decreased over time $(r=-0.66, p=0.006)$.

The Wilks' test of group means for the coverage of Halophila johnsonii over site was significant $(\alpha=0.05)$. However, no indication of a north-south or other trend in coverage over time emerged with this approach.

We do not see similar patterns when the data were summarized by year for all observations of Halophila johnsonii (Fig. 3A), nor for those samples in which coverage of $H$. johnsonii is non-zero (Fig. 3B).

\section{Seasonal variability}

Halophila johnsonii is a perennial species showing no apparent seasonal pattern based upon our longterm data set. Although a perennial species, H. johnsonii does exhibit some winter decline. However, during some exceptionally mild winters, as in the winter of 2004, H. johnsonii can maintain or even increase its abundance.

Summer mean \pm SD percent coverage was $3.2 \pm$ $13.8 \%(\mathrm{~N}=6351)$. Winter mean percent coverage was $2.3 \% \pm 11.7 \%(\mathrm{~N}=3330)$. The mean season differences were significant; however, PES $=0.001$. The variance $F$-test rejected the hypothesis of homogeneity of variance over season $(\alpha=0.001)$ and no transformation could stabilize the variances. However, the fluctuations in average density of $H$. johnsonii over 14 summers show the potential for cyclical behavior of a 2 to $3 \mathrm{yr}$ increase followed by a $1 \mathrm{yr}$ decrease (Fig. 4A), while the winter season shows no such cyclicity (Fig. 4B).

Of the total 828 non-zero samples of the presence of Halophila johnsonii, 602 occurred during the $14 \mathrm{yr}$ of summer sampling. These 602 samples had a mean $\pm \mathrm{SD}$ coverage of $33.7 \pm 31.5 \%$. This mean summer 
occurrence was virtually the same as that for the 226 winter occurrences, which had a mean coverage of $33.6 \pm 31.3 \%$. Based on the total 828 samples, no seasonal differences $(\mathrm{p} \geq 0.05, \mathrm{PES}=0.000)$ in $H$. johnsonii coverage were detected. However, because the variability in year and depth category subsets of the data was consistently larger in the winter, we examined seasonal models by year (Table 3 ).

Both with all the data and with only non-zero data (Table 3), there were significant seasonal differences in 2000, 2002, and 2004. Summer coverage was greater than winter in 2000; winter was greater in 2002 and 2004. Tests on seasonal differences within depth categories by year could not be performed because of insufficient degrees of freedom.

\section{Geographic or regional variability}

Although individual site differences can provide meaningful insight into biological changes in Halophila johnsonii, an analysis and summary of each site was neither helpful nor possible. Many early studies established that seagrass species are comprised of populations adapted to the selective influence of local habitat conditions over their distributional range. Thus, as an alternative, we examined these site differences based upon groupings of sites into regions of North, Mid and South range. Analyzing the significant yearly effect separately for each of the 3 geographic regions shows that the variability among the North sites was minimal in comparison with that in the South partly because the mean is much smaller in the North (Fig. 5) and that the Mid region was not statistically or ecologically separable from the other two. In all subsequent univariate models that involved region, we used only the 2 distinct regions of North and South.

There were 3564 total samples for Halophila johnsonii coverage in the North region and 834 in the South region over time, with differences in $\mathrm{N}$ attributable to fewer and shorter transects in the South. General linear models were fitted to the observations with factors of geographic region, season, and time with their interactions. Considering only the 2 areas of North and South as a 1-degree of freedom regional factor in this
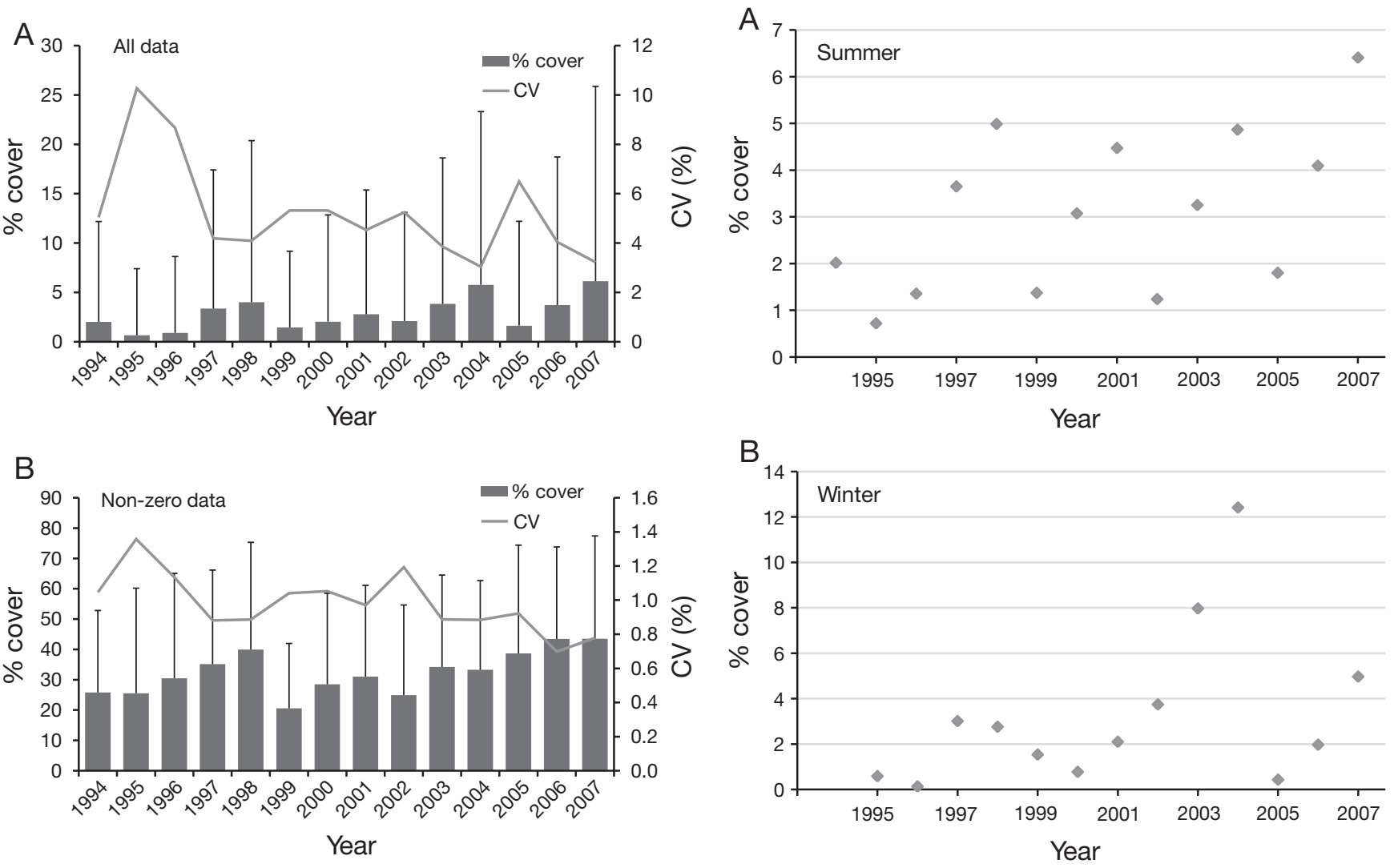

Fig. 3. Halophila johnsonii. Average percent cover (+ SD) and the coefficient of variation (CV), by year for (A) all data, and (B) those samples in which coverage of $H$. johnsonii is non-zero

Fig. 4. Halophila johnsonii. Average percent cover from (A) $14 \mathrm{yr}$ of summer data showing cyclical behavior of a 2 to $3 \mathrm{yr}$ increase followed by a 1 yr decrease, and (B) 13 yr of winter data showing no cyclicity. Note differences in scales 
model yielded a significant result for each of the factors of year, season, region, and interactions. The differences between North and South within each season were distinct, and interaction was statistically significant. However, the PES value for season was only 0.004, while time and regional PES values were 0.03 and 0.06 respectively. Summary descriptive statistics are given in Table 4 . The overall model explained only approximately $11 \%$ of the total variability in this dataset.

We then attempted to model North and South areas separately on the data set composed of only non-zero occurrences of Halophila johnsonii, with factors of season, depth categories, and year (Fig. 5). All tests were non-significant.

Examining the data by year for seasonal and regional differences and their interaction yielded models with $\mathrm{R}^{2}$ values ranging only from 0.03 to 0.27 (unadjusted) and non-significance for season in all but 3 years (2002, 2003, and 1994 were not applicable). In each case for which there were sufficient data, the regional difference had $p=0.000$ with PES values ranging from 0.016 to 0.223 . Interaction of region and season was non-significant except for years 2002 to 2004 .

\section{Variation over depth}

Depth of occurrence ranged from 0.03 to $2.5 \mathrm{~m}$. When data from all transects were combined, there was no obvious correlation of Halophila johnsonii density with depth or season. When all depths of occurrence were standardized (as percent of maximal depth of that transect), $H$. johnsonii was more abundant in the deeper part of the transects. Most (85.9\%, or 651 out of 758 observations) non-zero occurrences of $H$. johnsonii were at $\geq 70 \%$ of maximal transect depth; over half $(57.8 \%$, or 438 of 758$)$ were at $\geq 90 \%$ of maximal depth.

Adding standardized categories of depth to the model $(\mathrm{N}=4244)$ showed that depth category was highly significant ( $p=0.000$ with $9 \mathrm{df}$ ), with PES of only 0.014 . Year-by-depth interaction had a PES of 0.082 with densities higher at the deeper sites. This overall model explained approximately $27 \%$ of the variability in the system. All factors and interactions were significant due to the large sample sizes. There were insufficient degrees of freedom to provide meaningful information on depth categories within models for each year by season and/or region.
Over the 10 depth categories, the mean coverage of Halophila johnsonii varied from about 0.1 to $4.0 \%$. Occurrences as well as mean values increased as depth increased (Fig. 6A). Regression on means gave an $\mathrm{R}^{2}$ adjusted value of 0.97 with a standardized coefficient of 0.99. As depth increased, the variance of $H$. johnsonii coverage also increased significantly but not monotonically, whereas the coefficient of variation decreased with a slope of -0.91 and adjusted $\mathrm{R}^{2}$ of 0.803 (Fig. 6A).

If we consider all occurrences of coverage by depth category of Halophila johnsonii, our model yielded $\mathrm{R}^{2}=$ 0.04, while the non-zero presence-only data modeled by depth category had $\mathrm{p}=0.000$ and $\mathrm{PES}=0.076$ (Fig. 6B). This PES value is in contrast to the model for all data of $H$. johnsonii which gave PES $=0.007$.

Because of the very large percentage of zero values, we also considered only those quadrats in which Halophila johnsonii was non-zero or present to address questions of $H$. johnsonii behavior when and where the species occurs. Examining seasonal variability within standardized depth categories, on average we found no significant seasonal difference. The interaction of depth category with season showed no significant trend over time $(p>0.05)$ in winter, while summer had a significant change over depth from lows in depth categories 1 to 3 to a high attained by category 10. For only the non-zero values of $H$. johnsonii, neither season showed any trend for coverage over depth (Fig. 7). In many depth categories, the winter mean was larger than the corresponding summer means. In 


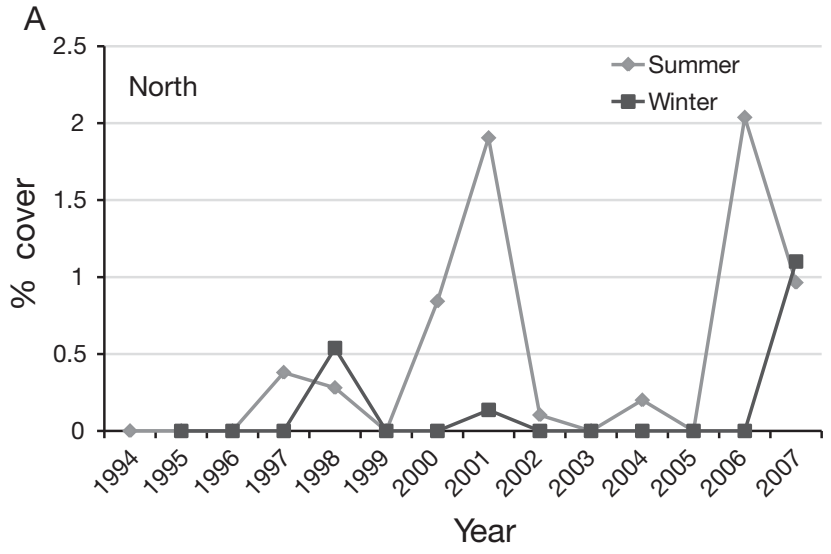

B

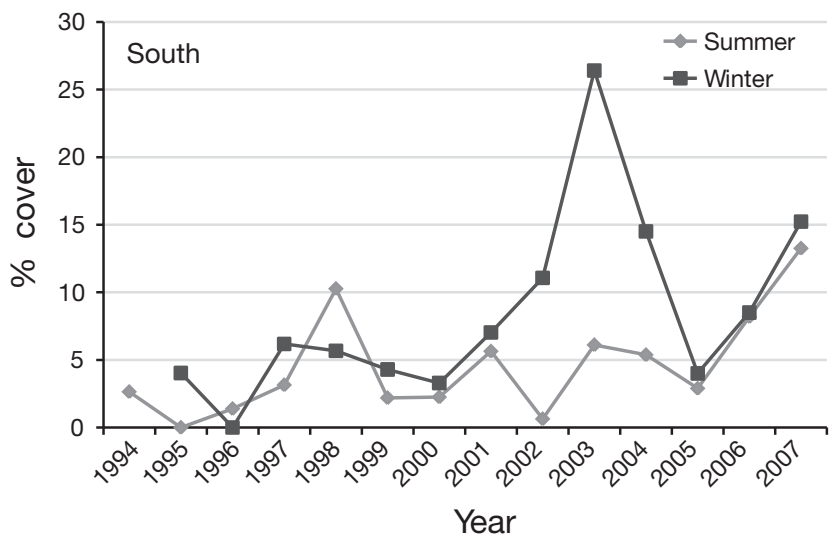

Fig. 5. Halophila johnsonii. Seasonal means (summer and winter) for (A) North and (B) South regions for non-zero data. Note differences in scales

addition, winter was more highly variable than summer for all categories, approximately 1.5 to 2 times larger in absolute value, but sample sizes are small.

\section{Visual estimates of canopy coverage of Halophila johnsonii versus counts}

There were 6836 visually estimated values of the density of Halophila johnsonii. Visual estimation of canopy coverage of individual species did not begin until 1998. The correlation between the visual estimates and the coverage values based on counts for the same quadrats was 0.80 , significant at the $\mathrm{p}=$ 0.0001 level. This correlation led to a coefficient of determination $\left(\mathrm{R}^{2}\right)$ of 0.64 , which can be interpreted to mean that approximately $64 \%$ of the variability in counted coverage was captured by the visual estimates. We used regression models by year and season to examine possible differences in the predictability of coverage with visual estimates. Regression statistics by year and season show that each of the $R^{2}$ values is significant at the $\alpha=0.0001$ level, except for summer of 2000 when $\mathrm{p}=0.041$ based on $\mathrm{N}=96$. No model could be fitted for winter of 2005 $(\mathrm{N}=59)$. The $\mathrm{R}^{2}$ values for these models show that estimates prior to 2000 were lower possibly because of a learning curve for this visual estimation procedure. Regression estimates from 2000 to present showed that 76 to $98 \%$ of the total variability in coverage by season each year can be explained using visual estimates. There was no trend in decreasing or increasing ability to estimate coverage by depth or over years.

\section{Interaction of other seagrass species with Halophila johnsonii}

\section{Coexistence with canopy-forming species}

Included in the transect data collected were coverage data for each of the other individual seagrass species found in the IRL. These species are Halodule wrightii Ascherson, Syringodium filiforme Kützing, Thalassia testudinum Banks ex König, Ruppia maritima L., Halophila engelmannii Ascherson, and Halophila decipiens Ostenfeld. In addition, we recorded algal coverage, both drift macroalgae and the attached macroalga Caulerpa prolifera.

We separated these data into those species we termed 'canopy-forming' and 2 small species in the genus Halophila. We examined these 2 groups and analyzed them separately for possible relationships with Halophila johnsonii. Included in the canopy-forming species group are those species whose growth patterns could possibly crowd or out-compete the lowgrowing $H$. johnsonii. The canopy-forming species we included are Halodule wrightii, Syringodium filiforme, and Thalassia testudinum.

Upon initial examination of all samples over time and space we found very little, if any, of the variability in the coverage or non-coverage of Halophila johnsonii to be explained by coexistence with canopyforming species. Using all 9681 samples, the overall

Table 4. Descriptive statistics for total number and percent cover of all Halophila johnsonii samples for summer and winter seasons by geographical region

\begin{tabular}{|c|c|c|c|c|c|c|}
\hline \multirow[t]{2}{*}{ Region } & \multirow[t]{2}{*}{ Season } & \multirow[t]{2}{*}{$\mathrm{N}$} & \multirow{2}{*}{$\begin{array}{c}\text { Mean } \\
(\% \text { cover })\end{array}$} & \multirow{2}{*}{$\mathrm{SD}$} & \multicolumn{2}{|c|}{$\longrightarrow$ PES -} \\
\hline & & & & & Region & Season \\
\hline \multirow[t]{2}{*}{ North } & Summer & 2344 & 0.48 & 5.24 & \multirow[t]{2}{*}{0.030} & \multirow[t]{4}{*}{0.004} \\
\hline & Winter & 1220 & 0.13 & 2.08 & & \\
\hline \multirow[t]{2}{*}{ South } & Summer & 505 & 4.98 & 15.94 & \multirow[t]{2}{*}{0.06} & \\
\hline & Winter & 329 & 6.29 & 17.84 & & \\
\hline
\end{tabular}


correlations of $H$. johnsonii with all 3 species were significant again because of large sample size. For correlations of species pairs and groups, we eliminated pairs of missing values, which accounts for the discrepancy in the sample sizes given below. Correlation of H. johnsonii percent cover with Halodule wrightii was $\mathrm{r}=-0.08(\mathrm{p}<0.001, \mathrm{~N}=9674)$, Syringodium filiforme, $\mathrm{r}=-0.10(\mathrm{p}<0.001$, $\mathrm{N}=9675$ ), and Thalassia testudinum, $\mathrm{r}=$ $-0.06(p<0.001, N=9677)$. However, it must be recalled that the high percentages of cooccurring zero values, although valid samples, will increase the coefficient in a correlation. For example, the percentage of the zero values was $34.9 \%$ for $H$. wrightii, $63.9 \%$ for S. filiforme, and $81.3 \%$ for T. testudinum. When we used the non-zero values of coverage by each species, this left us with sample sizes of 6299, 2956, and 1129, respectively. Based upon the non-zero totals, median coverage of $H$. wrightii was $38.8 \%, S$. filiforme $20.1 \%$, and T. testudinum $5.6 \%$.

These sample sizes were further reduced when co-occurrence of more than one canopyforming species with Halophila johnsonii was considered. There were $\mathrm{N}=501$ non-zero values of presence of $H$. johnsonii with at least one of these canopy-forming species and 295 monospecific values without any of the canopy-forming species. The mean \pm SD cover of co-occurrences with other species was $35.4 \pm 32.4 \%$, while the mean of the monospecific observations of $H$. johnsonii was $30.0 \pm$ $29.0 \%$. Despite the observed significance $(\mathrm{p}=$ 0.018 ), the predictive value for these 2 groups was poor (PES was only 0.007), predicting only $48 \%$ of each group correctly, slightly worse than a coin toss.

We continued this analysis by identifying not only the particular canopy-forming species, but also species groups within each of the seagrass beds that also contained Halophila johnsonii. We investigated whether the coverage of $H$. johnsonii was equal when co-occurring just with a single species or with groups of these canopy-forming species. The model with Syringodium filiforme had too few degrees of freedom. The model with $H$. johnsonii and Halodule wrightii data was not significant. For Thalassia testudinum, the effect of year was significant over depth categories 3 through 10 , not by season or season $\times$ year; however, the sample sizes were too small to be considered useful for the latter tests.
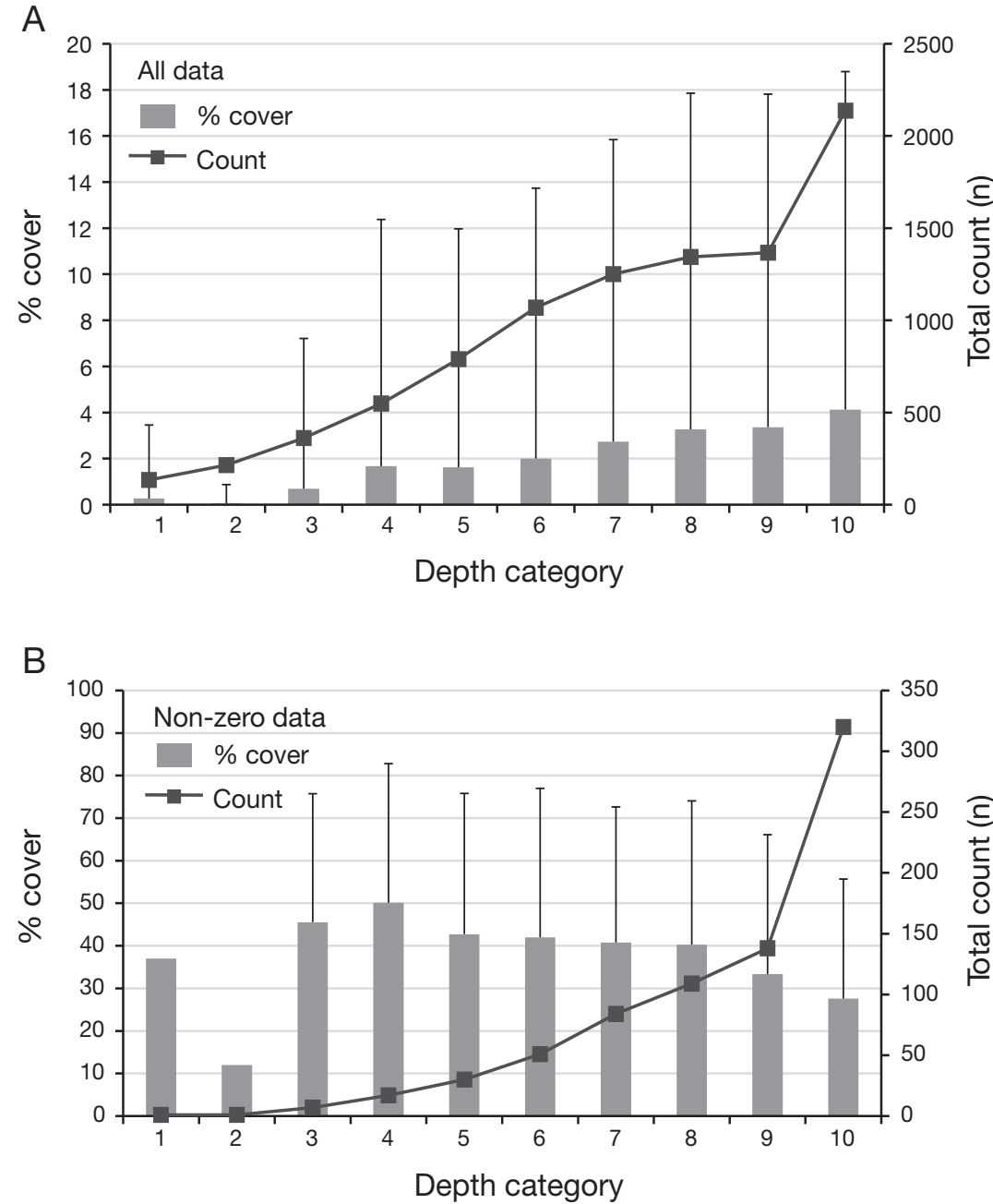

Fig. 6. Halophila johnsonii. Average percent cover (+1 SD) over the 10 standardized depth categories, based on percent of maximal depth at each site, for (A) all data and (B) non-zero data.

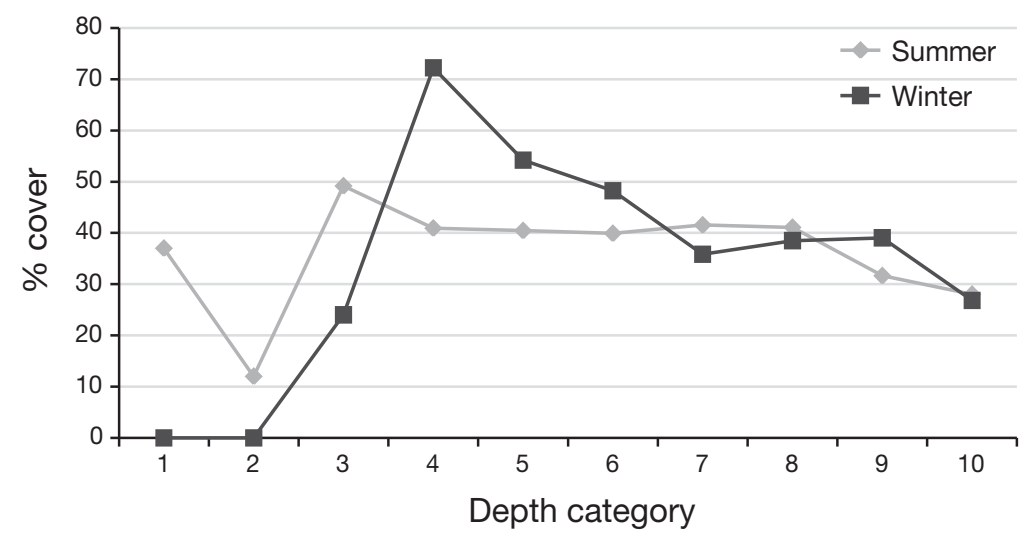

Fig. 7. Halophila johnsonii. Seasonal data over the 10 standardized depth categories, based on percent of maximal depth at each site, for (A) all data and (B) non-zero data 
Examining these data by region and season with interaction showed no significant results for Halophila johnsonii coverage when co-occurring with any of the canopy-forming species alone or in combination. The variance of $H$. johnsonii for summer samples was 2.9 and $4.5 \%$ in winter when occurring with at least one of these species. Those samples of only $H$. johnsonii without any canopy-forming species yielded a variance of $7.2 \%$ in summer and $2.9 \%$ in winter. Although these summer-winter differences in variance were significant, there appeared to be no pattern of increase or decrease over time or space.

By year, correlations of Halophila johnsonii's coverage with and without canopy-forming species alone or in combination were mostly not significant, and only those with Thalassia testudinum and some with Halodule wrightii were slightly significant for some years, but all with PES values near zero. Correlations over seasons showed similar results of mostly non-significant and small differences.

\section{Coexistence with other species of Halophila}

There were 201 samples in which both Halophila johnsonii and $H$. decipiens were found together. Over these 201 samples, $H$. johnsonii had a mean \pm SD coverage of $26.6 \pm 12.7 \%$. Of all the samples, there were only 9 for which $H$. engelmannii co-occurred with $H$. johnsonii. There were no significant differences within or between any of these groupings of H. johnsonii alone or with other species of Halophila.

\section{DISCUSSION}

As first noted by Arber (1920), to survive, all seagrasses must (1) be adapted to life in saline conditions, (2) be capable of growth when completely submerged,

(3) be able to maintain an anchoring system to withstand wave action and tidal currents, and (4) have capacity for hydrophilous pollination.

Besides these general requirements, there obviously must be an additional fifth aspect of biological interactions at the local scale. Seagrass species must either maintain successful competitive status or occupy different habitats, e.g. depths. Our results on the erratic, sparse, but persistent life habits of Halophila johnsonii show that this localized endemic species has been successful at the first 3 of these aspects, but in its own unique manner. Somehow, H. johnsonii survives without apparent sexual reproduction. It is clear from our study that $H$. johnsonii is opportunistic in the sense that it seems to avoid direct competition with taller light-shading canopy-forming species as part of its survival strategy. However, coverage does not appear to correlate predictably either with coverage of the canopy-forming species or with coverage of other species of Halophila.

Our analysis of over 9000 samples for Halophila johnsonii clearly shows that generalized prediction of this species' distribution and density, or coverage, is severely limited both spatially and temporally. Based on anecdotal observations, $H$. johnsonii abundance was assumed seasonal, with regulatory surveys required in spring/summer (NMFS 2002). However, statistical non-significance of these average seasonal differences is the rule. From any combination of factors, we cannot predict exactly where or when the densest coverage will appear. Indeed, we cannot predict the particular set of conditions that determine either occurrence or abundance.

Effect size is generally overlooked in statistical analyses. Statistical significance, or observed P-value, actually provides little helpful information on differences over space or time in seagrass assemblages. The test results, as we have seen, depend upon the sample size, and test (alpha) level (= power), at which the test was performed, as well as the difference between the means of the factors being tested. To reject a null hypothesis of no difference, whether spatial, yearly, seasonal or other, is to reject that the size of the differences is actually zero. But because all nature varies, it is clear that such a strict hypothesis is patently false before any actual test is performed. Clearly, hypothesis test results do not provide any indication of the magnitude of the real, ecological difference, which is why we incorporate an effect size measure. We saw that when we tested hypotheses using the entire 9681 samples, our results were significant, yet when we delved deeper into the reasons behind this significance on local levels, we found non-significance. Thus, with a large enough sample size, there is always a data set that will provide for the rejection of a hypothesis. However, the PES, a standardized measure of effect size or difference, allows for comparisons regardless of the sample size differences.

Effect size values have no standard that has proven useful across all applications or fields of research. Cohen (1977) provided guidelines as an initial convention for use as operational definitions of 'small', 'medium', and 'large' effect sizes. Unfortunately, these conventions of $0.10,0.25$, and 0.45 became, over time, a standard in some application areas, despite warnings by Cohen (1977) that such values should be developed as appropriate for a specific problem or field of research. Hayek \& Heyer (2005) devised a set of values specifically for morphological studies of the frog Leptodactylus spp. that are proving appropriate across other amphibian species. Their sizes were $0.20,0.45$, and 0.70 . A 
review of Table 3 shows that neither of these sets of values would be appropriate for $H$. johnsonii studies. For example, Table 3 shows that data in 2001 had a minute PES value of 0.008 despite a significant seasonal difference ( $N=673)$, while in 1996 the seasonal difference was not significant for non-zero data despite a larger PES of $0.135(\mathrm{~N}=22)$. Clearly, these apparently contradictory test results are related to sample size. Here we propose supplementing statistical tests in seagrass and other ecological studies with a measure of effect size, hopefully prospective, but at least retrospective.

Because this seagrass study is the first to our knowledge to incorporate such a measure, we also propose a set of initial conventions for definition of 'small', 'medium', and 'large' effect size, specifically for percent cover of seagrass species, and Halophila johnsonii in particular. These proposed values, based upon our $14 \mathrm{yr}$ of sampling and tests reported herein are: small = 0.04 ; medium $=0.10$; large $=0.18$. Consideration of these values prospectively, i.e. before field work and testing, will allow researchers to determine appropriate sample sizes for field work to test adequately their hypotheses and avoid the problematic results of statistical significance without ecological significance or importance. When used in this way for future seagrass studies, we expect these preliminary effect size cut points will be refined. Such a study is underway for Syringodium filiforme.

We continue our discussion by presenting a summary from the broadest sweep through to the smaller spatial and temporal scales over which we sampled.

\section{Broad-scale results}

The average percent cover of Halophila johnsonii has been increasing over time (Table 2), with accompanying changes in both temporal and spatial variability. This trend has led to an approximately 12 yr interval with relatively stable but high coefficients of variation, indicating that this species may be approaching stability in density over time. The fluctuations in mean summer abundance of $H$. johnsonii might possibly be indicative of a 3 to 4 yr temporal cycle consisting of 2 to 3 yr of increase followed by a rapid 1 yr decrease (Fig. 4A). Additional monitoring is needed to confirm this potential tendency and to determine what drives the synchrony. Because we began this study, as with most monitoring studies, with a haphazard start date, we have no way to know if this monitoring effort began at an actual end point of a cyclical period. Further long-term study needs to be done to develop more predictive results for management purposes. Additional recent data, through summer 2008, have not apparently changed any of these patterns.
There is no meaningful seasonal variability in the density of Halophila johnsonii over the studied geographic range or over years. Although there was anecdotal indication of seasonal difference, and some winter decline in certain years, as well as inequity between the Northern and Southern regions, we found these differences were neither ecologically meaningful nor useful for predictive purposes. In winter, the variance of coverage of $H$. johnsonii was $190.9 \%$, while in summer it was $137.9 \%$. These variances are significantly different, as are the means, but in both cases the PES is close to zero. We hypothesize that this difference in variance is the underlying reason why so many observers believe there to be a seasonal difference in coverage values when there is no meaningful observable seasonal effect in general.

Introducing covariates of depth or distance from shore did not increase predictability. Because our transects were all run from shore to the deep edge of seagrass, but each site had its own unique configuration of bottom topography, we tried a statistical adjustment on depth to consider whether we could detect significant differences. We calculated a new variable of standardized depth, which used the observed depth as a percentage of the maximal depth at that site. Using this standardized depth measure, we found Halophila johnsonii more abundant near the deep edge of the transects. However, this increase in coverage was not monotonic, but variability increased significantly with depth (Fig. 6). This pattern did not differ between seasons.

Means of sites throughout the range of $H$. johnsonii clearly are larger or smaller than one another and in some cases statistically different. However, we could not generalize these results over all sites. When we segregated sites into regions of the IRL, we found some differences. There were significant seasonal differences within region, but these were coupled with such minute observed PES values as to obviate any ecological meaning. There was a smaller number of samples in the winter in both North and South, and the mean coverage in the North was always smaller than that in the South regardless of season (Table 4). However, in neither region is the coverage significantly different between seasons.

\section{Local or small-scale results}

There is a reasonably high correlation of our field visual estimates of canopy coverage with our counted coverage values, as measured by counts of occupied cells in the quadrat. Approximately 76 to $98 \%$ of the variability in these values, over space and time, can be accounted for with the rapid visual estimation tech- 
niques used in this study, based on measurements from 2000 to 2007. This fact can possibly be exploited for quick survey results in other areas because it was a consistent result over time and space.

Both the density and average coverage of Halophila johnsonii increased significantly over our 10 depth categories based upon maximal depth at each site (Fig. 6). Regression showed that the standardized coefficient (R) was highly significant at 0.912 . This increase, however, is not monotonic, which means that prediction of trend across all depth categories is not possible for individual cases. On average, there is no seasonal variability within these standardized depth categories. Examination of only non-zero coverage values (Fig. 7B) shows a significant trend over depth only in the summer, but with PES close to zero. Further longterm study is needed to confirm these patterns.

We examined the distributions and co-occurrences of Halophila johnsonii with the canopy-forming species Halodule wrightii, Syringodium filiforme, and Thalassia testudinum for possible insight into differences in coverage of $H$. johnsonii. Upon initial examination of all data over space and time, we found very little if any variability of $H$. johnsonii coverage that could be attributed to its co-occurrence with these species. This lack of detectable relationship is due to high proportions of zero values. We had expected that the incidence of $H$. johnsonii with $S$. filiforme would be negatively correlated, given the smaller stature of $H$. johnsonii and its comparative rarity. This was not the case. However, a general linear modeling of the co-occurrence of $H$. johnsonii and $S$. filiforme showed significance by year and year by season. When we examined this pattern by depth, significance for these 2 species increased with depth, but PES decreased from 0.121 at $60 \%$ of maximal depth to 0.03 at $100 \%$ of maximal depth. More work needs to be done on this question of the relationships of other species with $H$. johnsonii.

\section{CONCLUSIONS}

Finally, although we did find spatial and temporal partitions in which periodicities or cyclicities occurred, in general, test results do not provide for predictability of Halophila johnsonii's coverage, despite $14 \mathrm{yr}$ of monitoring. However, we conclude that there is community stability despite, and as a result of, this local small-scale unpredictability of $H$. johnsonii. This species occupies the estuary by filling in niche spaces within the coverage of other species; it extends the depth range of the prevalent seagrass ecosystem (R. W. Virnstein pers. obs., R. Ellis, University of Florida, pers. comm.), and as Heidelbaugh (1999) pointed out, $H$. johnsonii provides additional habitat value within the IRL. We have seen that $H$. johnsonii survives and indeed summer values appear even to have a slight increasing trend with a possible 3 to 4 yr cyclical pattern of increasing and decreasing average density. However, although the patchiness of $H$. johnsonii's distribution, both spatially and temporally, is becoming clearer, distribution and density are not yet predictable. Buzas \& Hayek $(2000,2002)$ found that Foraminifera in the IRL behave in a comparable manner to that of $H$. johnsonii in some respects. That is, these benthic protists, which live within the same seagrass beds in the IRL, survive and thrive according to a selective life strategy of stability over large amounts of space and time achieved by large amounts of variability over small spatial and temporal scales. Thus, based upon the results from this long-term and thorough data set, we propose a model of asynchronous, 'pulsating patches' in space and time to describe parsimoniously and effectively the survival strategy of H. johnsonii.

Acknowledgements. This work would not have been possible without the hard work of the IRL field staff, particularly L. Hall for her dedication to finding this small species and C. Akers for many hours spent managing the database. J. Miller, L. Battoe, and P. Kinser provided preliminary and helpful reviews. Four anonymous reviewers helped us to avoid many errors and improved the manuscript. This is SEA contribution no. 15.

\section{LITERATURE CITED}

Arber A (1920) Water plants. A study of aquatic angiosperms. University Press, Cambridge

Buzas MA, Hayek LC (2000) A case for long-term monitoring of the Indian River, Florida: foraminiferal densities, 1977-1996. Bull Mar Sci 67:805-814

Buzas MA, Hayek LC (2002) Foraminiferal densities over five years in the Indian River Lagoon Florida: a model of pulsating patches. J Foraminiferal Res 32:68-93

Cohen J (1977) Statistical power analysis for the behavioral sciences. Academic Press, New York

Eiseman NJ, McMillan C (1980) A new species of seagrass, Halophila johnsonii, from the Atlantic coast of Florida. Aquat Bot 9:15-19

Gilmore RG (1985) The productive web of life in the estuary. In: Barile DD (ed) The Indian River Lagoon: Proceedings of the Indian River Resources Symposium. Sea Grant Project No. I.R. 84-28, Marine Resources Council of East Florida, Florida Institute of Technology, Melbourne, FL

Greig-Smith P (1983) Quantitative plant ecology. In: Anderson DJ, Greig-Smith P, Pitelka FA (eds) Studies in ecology, Vol 9. University of California Press, Berkeley and Los Angeles, CA

Hall LM, Hanisak MD, Virnstein RW (2006) Fragments of the seagrasses Halodule wrightii and Halophila johnsonii as potential recruits in Indian River Lagoon, Florida. Mar Ecol Prog Ser 310:109-117

Hayek LC, Heyer WR (2005) Determining sexual dimorphism in frog measurement data: integration of measurement error, statistical significance, biological significance, and 
effect size. An Acad Bras Cienc 77:45-76

Heidelbaugh WS (1999) Determination of the ecological role of the seagrass Halophila johnsonii; a threatened species in southeast Florida. PhD dissertation, Florida Institute of Technology, Melbourne, FL

Kenworthy WJ (1992) The distribution, abundance and ecology of Halophila johnsonii Eiseman in the lower Indian River, Florida. Final Report to the Office of Protected Resources, National Marine Fisheries Service, Silver Spring, MD

Morris LJ, Hall LM, Virnstein RW (2001) Field guide for fixed transect monitoring in the Indian River Lagoon. St. Johns River Water Management District, Palatka, FL

NMFS (National Marine Fisheries Service) (2002) Recovery plan for Johnson's seagrass (Halophila johnsonii). Prepared by the Johnson's Seagrass Recovery Team for the National Marine Fisheries Service, Silver Spring, MD

Editorial responsibility: Hans Heinrich Janssen, Oldendorf/Luhe, Germany
Phillips RC (1960) Observations on the ecology and distribution of the Florida seagrasses. Professional Paper Series \#2. Florida State Board of Conservation Marine Laboratory, St. Petersburg, FL

SPSS (2007) SPSS release 16.0 for Windows. SPSS, Chicago, IL

Virnstein RW, Hall LM (2009) Northern range extension of the seagrasses Halophila johnsonii and Halophila decipiens along the east coast of Florida, USA. Aquat Bot 90:89-92

Virnstein RW, Morris LJ (1996) Seagrass preservation and restoration: a diagnostic plan for the Indian River Lagoon. Tech Memo \#14. St. Johns River Water Management District, Palatka, FL

Virnstein RW, Morris LJ (2007) Distribution and abundance of Halophila johnsonii in the Indian River Lagoon: an update. Tech Memo \#51. St. Johns River Water Management District, Palatka, FL

Submitted: December 17, 2008; Accepted: March 31, 2009 Proofs received from author(s): June 1, 2009 